\title{
Mercado de Trabalho conjuntura e análise
}

ANO 27 | março de 2021

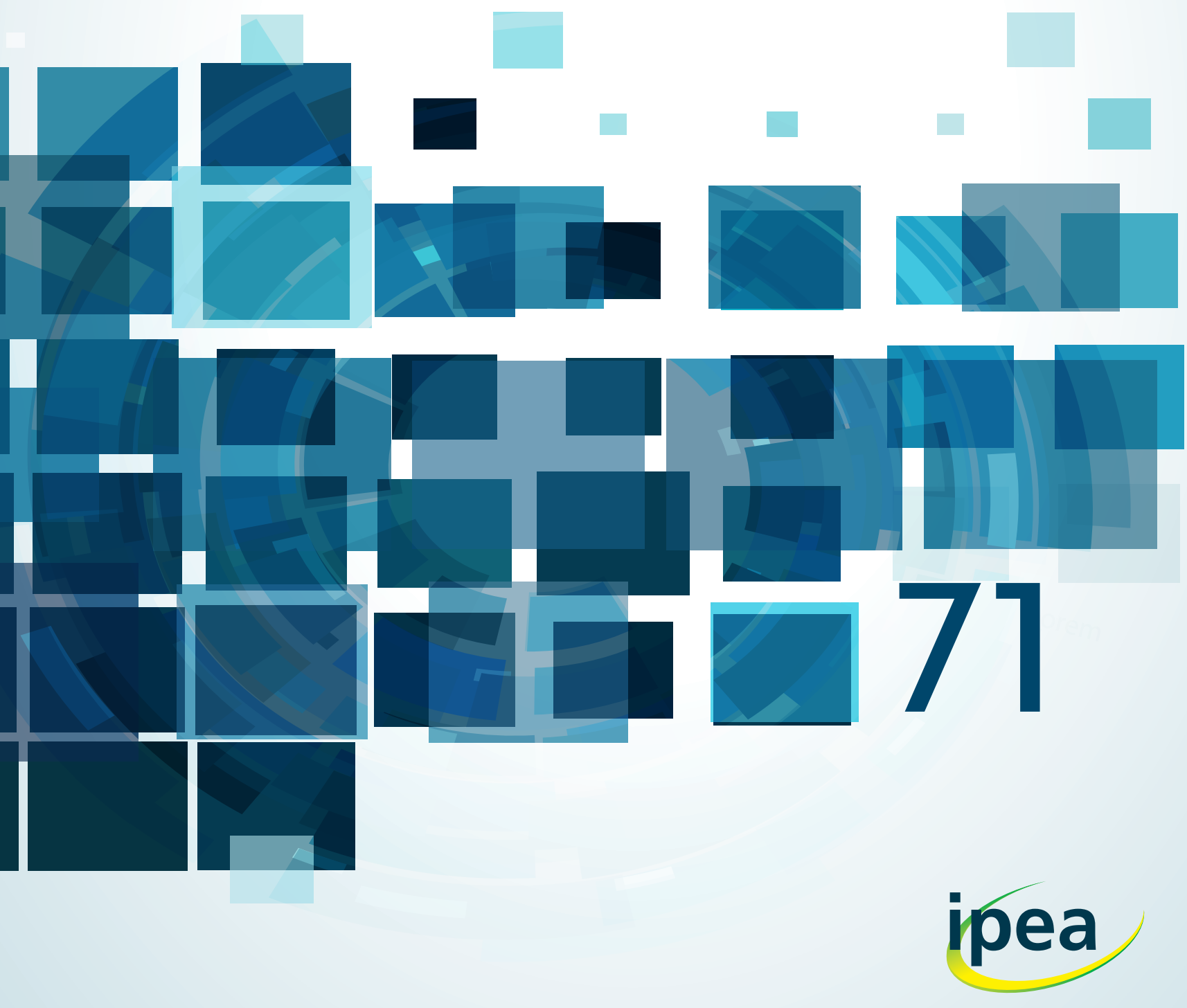




\author{
Governo Federal \\ Ministério da Economia \\ Ministro Paulo Guedes
}

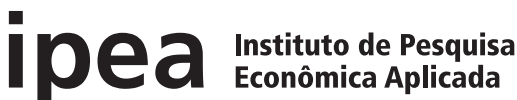

Fundação pública vinculada ao Ministério da Economia, o Ipea fornece suporte técnico e institucional às ações governamentais - possibilitando a formulação de inúmeras políticas públicas e programas de desenvolvimento brasileiros - e disponibiliza, para a sociedade, pesquisas e estudos realizados por seus técnicos.

\section{Presidente}

Carlos von Doellinger

Diretor de Desenvolvimento Institucional

Manoel Rodrigues Junior

Diretora de Estudos e Políticas do Estado,

das Instituições e da Democracia

Flávia de Holanda Schmidt

\section{Diretor de Estudos e Políticas}

Macroeconômicas

José Ronaldo de Castro Souza Júnior

Diretor de Estudos e Políticas Regionais, Urbanas e Ambientais

Nilo Luiz Saccaro Júnior

Diretor de Estudos e Políticas Setoriais de Inovação e Infraestrutura

André Tortato Rauen

Diretora de Estudos e Políticas Sociais

Lenita Maria Turchi

Diretor de Estudos e Relações Econômicas

e Políticas Internacionais

Ivan Tiago Machado Oliveira

Assessor-chefe de Imprensa e Comunicação

André Reis Diniz

Ouvidoria: http://www.ipea.gov.br/ouvidoria

URL: http://www.ipea.gov.br

\section{Mercado de Trabalho: conjuntura e análise}

\section{CORPO EDITORIAL}

Editor Responsável

Carlos Henrique Leite Corseuil

Felipe Mendonça Russo

Lauro Ramos

Sandro Pereira Silva

Sandro Sacchet de Carvalho

Equipe de Apoio

Bruna de Souza Azevedo

Carolina Lopes de Carvalho Vital

Gabriela Carolina Rezende Padilha

Maíra Albuquerque Penna Franca

Leandro Pereira da Rocha

\section{Membros}

C Instituto de Pesquisa Econômica Aplicada - ipea 2021
Mercado de trabalho : conjuntura e análise / Instituto de Pesquisa Econômica Aplicada; Ministério do Trabalho. - v.1, n.0, (mar.1996)- .- Brasília: Ipea: Ministério do Trabalho, 1996-

Irregular (de 1996-2008); Trimestral (de 2009-2012); Semestral (a partir de 2013).

Título da capa: Boletim Mercado de Trabalho (BMT)

ISSN 1676-0883

1. Mercado de Trabalho. 2. Estatísticas do Trabalho. 3. Brasil. 4. Periódicos. I. Instituto de Pesquisa Econômica Aplicada. II. Brasil. Ministério do Trabalho.

CDD 331.1205

As publicações do Ipea estão disponíveis para download gratuito nos formatos PDF (todas) e EPUB (livros e periódicos). Acesse: http://www.ipea.gov.br/portal/publicacoes

As opiniões emitidas nesta publicação são de exclusiva e inteira responsabilidade dos autores, não exprimindo, necessariamente, o ponto de vista do Instituto de Pesquisa Econômica Aplicada ou do Ministério da Economia.

É permitida a reprodução deste texto e dos dados nele contidos, desde que citada a fonte.Reproduções para fins comerciais são proibidas. 


\section{TECNOLOGIAS SOCIAIS E HABITAÇÃO: ANÁLISE DAS TECNOLOGIAS HABITACIONAIS CERTIFICADAS PELA FUNDAÇÃO BANCO DO BRASIL'1,2,3}

Graziela Zucoloto 4

Larissa Pereira ${ }^{5}$

Leonardo Szigethy ${ }^{6}$

\section{INTRODUÇÃO}

O deficit habitacional brasileiro encontra-se acima de 7 milhóes de moradias, de acordo com a Pesquisa Nacional por Amostra de Domicílios (PNAD) 2015, do Instituto Brasileiro de Geografia e Estatística (IBGE). Além desse elevado deficit, a alta quantidade de habitações inadequadas e insalubres, geralmente em periferias, assentamentos, favelas e ocupaçóes, apresenta-se como problema adicional.

Nesse contexto, o deficit habitacional no país, segundo estimativas da Fundação João Pinheiro (2018), ${ }^{7}$ é de 6,355 milhóes de domicílios, sendo 87,7\% em áreas urbanas e 12,3\% em áreas rurais. Compóem esse deficit: o ônus excessivo com aluguel (50\% dos domicílios), a coabitação familiar $(29,9 \%)$, as habitaçóes precárias $(14,8 \%)$ e o adensamento excessivo ${ }^{8}$ dos domicílios alugados (5,2\%). Ainda existem os domicílios inadequados ${ }^{9}$ que correspondem a 7,225 milhôes, desses: 1.871.473 estão em situação de inadequação fundiária, ${ }^{10} 213.732$ são ausentes de banheiro de uso exclusivo, 1.025 .717 estão em condição de adensamento excessivo ${ }^{11}$ e 834.722 contam com cobertura inadequada nos telhados. ${ }^{12}$

1. DOI: http://dx.doi.org/10.38116/bmt71/economiasolidaria2

2. Este texto é uma versão resumida do texto para discussão de mesmo nome que será publicado pelo Ipea.

3. Os autores agradecem os comentários de Mauro Oddo Nogueira, Pedro Miranda, Priscila Koeller, Rute Rodrigues e Sandro Silva, isentando-os de qualquer responsabilidade por eventuais erros e omissões.

4. Técnica de planejamento e pesquisa Diretoria de Estudos e Políticas Setoriais de Inovação e Infraestrutura (Diset) do Ipea. E-mail: <graziela.zucoloto@ipea.gov.br>.

5. Bolsista na Diset/lpea e mestranda em economia na Universidade Federal Fluminense (UFF). Email: <larissa.pereira@ipea.gov.br>.

6. Bolsista na Diset//pea. Email: <leonardo.szigethy@ipea.gov.br>.

7. Sobre o assunto, ver também Urushibata (2013).

8. "Domicílios próprios com mais de três moradores por dormitório" (FJP, 2018, p. 61).

9. "Para o cálculo dos domicílios inadequados, consideram-se apenas os domicílios duráveis urbanos, entendidos como tal aqueles que se situam na área urbana e não compõem o deficit habitacional" (FJP, 2018, p. 50).

10. Imóveis em terrenos não legalizados.

11. "Domicílios próprios com mais de três moradores por dormitório" (FJP, 2018, p. 61).

12. 0 conceito de deficit refere-se à imediata necessidade de construção de novas moradias, enquanto o de inadequação habitacional, aos domicílios que não proporcionam condições desejáveis de habitabilidade, mas não implica a necessidade de construção de novas unidades (Urushibata, 2013). 
No país, a maioria das casas ainda é edificada por meio da autoconstrução, muitas vezes por pessoas com baixo conhecimento técnico. Nesse cenário, a precariedade da iluminação e ventilação, o uso inadequado dos materiais, o desconforto térmico e a má qualidade das instalaçóes e estruturas comprometem as habitaçóes, impactando negativamente em questóes vitais como saúde e segurança (Bredenoord, 2016).

As atividades ligadas à construção civil também estão fortemente relacionadas à degradação ambiental, que ocorre por meio do consumo excessivo de recursos naturais, da demanda por matérias-primas industrializadas e da geração de resíduos. De acordo com Bredenoord (2016), para promover a habitação sustentável, as construçôes devem utilizar técnicas construtivas que respeitem o meio ambiente associadas aos recursos locais existentes, a partir dos quais tecnologias podem ser desenvolvidas e disseminadas para a produçáo de moradias que, ao mesmo tempo, sejam sustentáveis e acessíveis para os mais pobres. Na mesma linha, o Banco Mundial (2011) apresenta alternativas para reduzir os impactos da construção de moradias no Brasil e destaca a importância do aumento da reciclagem.

A partir desse cenário, que une elevado deficit habitacional, um número expressivo de habitações precárias e construções associadas a problemas ambientais, surge a necessidade de revisitar experiências inovadoras, a fim de encontrar alternativas para equacionar tais problemas.

Entre as alternativas existentes, encontram-se as tecnologias sociais (TS). As TS apresentam-se como alternativa para problemas estruturais das camadas mais excluídas da sociedade, trazendo soluçóes simples e efetivas para questóes diversas. Para Lassance Junior e Pedreira (2004), por sua simplicidade, as TS nem sempre são consideradas tecnologias, vistas apenas como boas práticas e, sem envolvimento governamental, dificilmente terão escala, tornando-se somente experimentos isolados.

Para Thomas (2009), as TS seriam uma forma de desenvolver, implementar e administrar tecnologias voltadas à resolução de problemas sociais e ambientais, e alcançariam um leque amplo de tecnologias de produto, processo e organização em áreas como alimentação, moradia, energia, água, transporte, entre outras. Para o autor, os atores fundamentais dos processos de desenvolvimento de TS seriam os movimentos sociais, as cooperativas populares, as organizaçóes não governamentais (ONGs), os centros públicos de pesquisa e desenvolvimento (P\&D), os governos, as empresas públicas e, em menor escala, as empresas privadas. 
A Fundação Banco do Brasil (FBB) está entre as principais instituições brasileiras de apoio ao desenvolvimento e à disseminação dessas tecnologias. Essa fundação define as TS como produtos, técnicas ou metodologias reaplicáveis, ${ }^{13}$ desenvolvidas em interação com a comunidade, as quais representam efetivas soluçóes de transformação social. Tais tecnologias seriam fruto dos esforços contínuos das comunidades impactadas por adversidades na busca por melhorias na qualidade de vida. $\mathrm{O}$ objetivo não seria originar necessariamente um novo produto, mas, sim, acrescentar um conjunto de conhecimentos, técnicas e metodologias que possam desenvolver soluçóes transformadoras e ser facilmente aplicadas, reaplicadas e apropriadas pela população, nos temas de alimentação, educação, energia, habitação, meio ambiente, recursos hídricos, renda e saúde (Zucoloto e Pereira, 2020).

As TS ganharam destaque na FBB a partir de 2001, ano da criação do Banco de Tecnologias Sociais (BTS). O BTS é uma base de informaçóes sobre as TS certificadas no âmbito do Prêmio Fundação Banco do Brasil de Tecnologia Social. Realizada a cada dois anos, essa iniciativa tem por objetivo identificar, certificar, premiar e difundir TS já aplicadas, implementadas em âmbito local, regional ou nacional. ${ }^{14}$ De acordo com o regulamento da última edição do prêmio, realizada em 2017, para ser certificada, a tecnologia deveria: i) estar em atividade há, pelo menos, dois anos; ii) possuir evidências efetivas de transformaçáo social; iii) estar sistematizada a ponto de tornar possível sua reaplicação em outras comunidades; iv) contar com a interação da comunidade na sua concepção ou ter sido apropriada por ela em seu desenvolvimento ou reaplicaçáo; e v) respeitar o protagonismo social, a cultura, o cuidado ambiental e a solidariedade econômica.

Podem concorrer ao prêmio instituições sem fins lucrativos, tais como instituiçóes de ensino e de pesquisa, fundaçóes, cooperativas, organizaçóes da sociedade civil e órgáos governamentais, de direito público ou privado, legalmente constituídas no Brasil ou nos demais países da América Latina ou do Caribe. Além do BTS, a FBB também apoia a difusão das tecnologias cadastradas por meio de editais específicos. Um dos exemplos foi o Projeto Moradia Urbana com Tecnologia Social (Muts). Em três fases, o projeto atendeu, desde 2014, 75 empreendimentos, distribuídos em 54 municípios de 19 estados, beneficiando mais de 160 mil moradores. ${ }^{15}$

Este texto analisa as TS cadastradas na FBB relacionadas ao setor habitacional entre 2003 e 2017, buscando compreender seus objetivos, principais características e problemas que buscaram solucionar.

13. A reaplicação é um dos conceitos-chave em torno das TS. É fundamental diferenciá-lo da simples cópia sem adaptações. Dadas as diferenças entre grupos e localidades, a difusão da TS deverá levar em consideração as demandas e características locais e a elas se adaptar, sendo, portanto, reaplicada, e não simplesmente replicada.

14. Para uma análise abrangente das tecnologias presentes no BTS, ver Corrêa (2010).

15. Mais informações em: <https://is.gd/NqQSHv>. Acesso em: 18 mar. 2021. 


\title{
2 TS DO SETOR HABITACIONAL
}

\author{
A análise baseia-se em 27 TS selecionadas por meio da definição habitação como tema principal ${ }^{16}$ \\ da tecnologia no BTS $^{17}$ (quadro 1).
}

\section{QUADRO 1}

\section{Descrição das TS habitacionais da FBB}

\begin{tabular}{|c|c|}
\hline TS & Descrição da TS \\
\hline $\begin{array}{l}\text { Autogestão e mutirão na construção de } \\
\text { moradias populares }\end{array}$ & $\begin{array}{l}\text { Construção das casas em regime de mutirão, com fabricação própria de lajes pré- } \\
\text { moldadas e blocos de concreto. }\end{array}$ \\
\hline $\begin{array}{l}\text { Bioconstrução comunitária em povos e } \\
\text { comunidades tradicionais }\end{array}$ & $\begin{array}{l}\text { Construção de moradias de convivência comunitária, compartilhadas por meio dos } \\
\text { materiais disponíveis na comunidade ou em sua proximidade. }\end{array}$ \\
\hline Bioconstrução para agricultura familiar & $\begin{array}{l}\text { Construção de moradias para agricultores familiares, que, por meio da bioconstrução, } \\
\text { promove a utilização e a reutilização racional de matérias-primas naturais e locais } \\
\text { abundantes nas propriedades rurais (terra, madeira, pedra, fibras vegetais), com o } \\
\text { objetivo de favorecer a apropriação e a autonomia tecnológica pelos agricultores, } \\
\text { minimizar o impacto ambiental e tornar a construção mais econômica. }\end{array}$ \\
\hline Calha alternativa & Confecção de calhas alternativas a partir de garrafas de plástico PET. \\
\hline $\begin{array}{l}\text { Caminhos da Favela (Caminos de la } \\
\text { Villa - Argentina) }\end{array}$ & $\begin{array}{l}\text { Portal multimídia interativo que torna visíveis as condições de vida em } \\
\text { bairros segregados, proporcionando aos seus moradores uma ferramenta } \\
\text { para o diagnóstico da comunidade das diferentes prestações de serviços e de } \\
\text { monitoramento e controle de obras públicas. }\end{array}$ \\
\hline Caprichando a Morada & $\begin{array}{l}\text { Construção, reforma ou ampliação de moradias no meio rural, englobando uma } \\
\text { série de ações junto aos agricultores familiares beneficiários dos programas } \\
\text { de habitação. Envolve mobilização e organização das famílias, elaboração dos } \\
\text { projetos e acompanhamento das obras e encontros para discutir temas relevantes } \\
\text { vinculados ao desenvolvimento rural, tais como sensibilização sobre os programas } \\
\text { habitacionais e orientação sobre princípios básicos de construção. }\end{array}$ \\
\hline $\begin{array}{l}\text { Casa fácil - kit de casa pré-fabricada e } \\
\text { laborterapia }\end{array}$ & $\begin{array}{l}\text { Sistema construtivo de baixo custo, com a implantação de uma fábrica de pré- } \\
\text { moldados e o uso de mão de obra prisional. }\end{array}$ \\
\hline $\begin{array}{l}\text { Casas adaptadas a eventos climáticos } \\
\text { extremos em áreas úmidas }\end{array}$ & $\begin{array}{l}\text { Construção de habitações modulares, móveis e de baixo custo, confeccionadas com } \\
\text { materiais sustentáveis, resistentes à água e ao fogo, que permitem a montagem e } \\
\text { a remontagem em caso de mudanças ambientais. }\end{array}$ \\
\hline $\begin{array}{l}\text { Construção de Habitação em } \\
\text { Assentamentos }\end{array}$ & $\begin{array}{l}\text { Construção de moradias via autoconstrução para famílias beneficiárias da } \\
\text { reforma agrária, por meio de uma metodologia de construção elaborada } \\
\text { coletivamente, baseada na racionalização e aproveitando-se dos recursos } \\
\text { disponíveis, na valorização do conhecimento da própria comunidade na } \\
\text { aplicação da mão de obra e no aperfeiçoamento do sistema construtivo. Ainda, } \\
\text { auxilia as famílias no acesso ao crédito. }\end{array}$ \\
\hline Construção de Moradias de Emergência & $\begin{array}{l}\text { Construção de moradias emergenciais em assentamentos precários para famílias } \\
\text { carentes, utilizando um módulo pré-fabricado construído sobre a base de pilotis. }\end{array}$ \\
\hline $\begin{array}{l}\text { Construção socioambiental com o uso } \\
\text { do BTC e captação de águas pluviais }\end{array}$ & $\begin{array}{l}\text { Construções saudáveis, de menores custos energéticos e impactos ambientais, } \\
\text { utilizando mão de obra local e fabricando blocos de terra crua, respondendo às } \\
\text { necessidades climáticas e socioculturais. }\end{array}$ \\
\hline $\begin{array}{l}\text { Experiência dos Agricultores Familiares } \\
\text { de Araponga/MG }\end{array}$ & $\begin{array}{l}\text { Promove auto-organização entre trabalhadores rurais e pequenos proprietários } \\
\text { para a compra conjunta de terra por meio de um arranjo coletivo de microfinanças. }\end{array}$ \\
\hline
\end{tabular}

16. A classificação temática das tecnologias é feita pela FBB.

17. Após esse levantamento, a FBB promoveu uma alteração nas TS cadastradas em seu banco. 
(Continuação)

\begin{tabular}{|c|c|}
\hline TS & Descrição da TS \\
\hline Gente Feliz & $\begin{array}{l}\text { Reformas de entidades sociais em condições de uso precárias, visando a: melhoria do } \\
\text { espaço; iluminação; ventilação e móveis; e a promoção de autoestima na população. }\end{array}$ \\
\hline $\begin{array}{l}\text { Habitação de Interesse Social com } \\
\text { materiais renováveis reaproveitáveis }\end{array}$ & $\begin{array}{l}\text { Construção de moradias de interesse social de baixo custo, com participação } \\
\text { da população beneficiária na fabricação de tijolos e na construção, utilizando } \\
\text { elementos construtivos intertravados, estruturais e de vedação, conformados } \\
\text { por prensagem a frio e materiais indígenas/locais (solo, fibras, bambu e resíduos } \\
\text { minerários, industriais e agrícolas). }\end{array}$ \\
\hline $\begin{array}{l}\text { Identificarte - Inclusão Postal Através } \\
\text { da Arte }\end{array}$ & $\begin{array}{l}\text { Produção e aplicação de placas numéricas de mosaico em casas e } \\
\text { estabelecimentos de moradores de áreas em risco social, visando promover o } \\
\text { endereçamento em comunidades. A técnica utilizada na produção é ensinada à } \\
\text { comunidade local por meio de oficinas. }\end{array}$ \\
\hline $\begin{array}{l}\text { Metodologia Social para Habitação } \\
\text { Popular-Aplicada nas Aldeias Indígenas } \\
\text { Pataxós }\end{array}$ & $\begin{array}{l}\text { Construção de moradias utilizando uma metodologia denominada modelo de } \\
\text { capacitação e gestão integradas das ações sustentáveis (Mintegra), visando à } \\
\text { melhoria imediata das condições de habitabilidade e à qualificação gradativa e } \\
\text { continuada dos beneficiários na construção civil, com a formação profissional de } \\
\text { pedreiros, e fazendo uso de técnicas e materiais característicos das comunidades. }\end{array}$ \\
\hline $\begin{array}{l}\text { Monitor de Pobreza e Desigualdade } \\
\text { (Monitor de Pobreza y Desigualdad - } \\
\text { Chile) }\end{array}$ & $\begin{array}{l}\text { Plataforma web de assentamentos precários (favelas) que consolida informações } \\
\text { socioterritoriais dessas regiões. }\end{array}$ \\
\hline $\begin{array}{l}\text { Moradia: Soluções Dignas e } \\
\text { Comunitárias }\end{array}$ & $\begin{array}{l}\text { Assistência técnica, construção e reforma usando estratégias e ferramentas } \\
\text { integradas para promover o acesso de populações de baixa renda à moradia } \\
\text { digna, segura e sustentável, incluindo crédito habitacional e produção e difusão } \\
\text { de soluções viáveis para famílias pobres. Para tanto, o projeto está atrelado à } \\
\text { implantação de uma fábrica de tijolos ecológicos. }\end{array}$ \\
\hline Mulheres em Construção & $\begin{array}{l}\text { Construção de moradias populares, destinadas às mulheres em condições de } \\
\text { vulnerabilidade social, proporcionando a estas qualificação profissional para o } \\
\text { trabalho na construção civil e a chance de construir uma moradia digna. Dentro do } \\
\text { programa, foi desenvolvida uma forma de fabricar tijolos ecológicos. }\end{array}$ \\
\hline $\begin{array}{l}\text { Planejamento Estratégico: uma } \\
\text { Possibilidade na Área de Habitação em } \\
\text { Carambeí/PR }\end{array}$ & $\begin{array}{l}\text { Identificação do perfil socioeconômico e cultural das famílias residentes em } \\
\text { bolsões de pobreza, zonas de risco e ocupações irregulares, objetivando promover } \\
\text { um planejamento urbano sustentável, que resultou na criação do Fundo Municipal } \\
\text { de Habitação e na construção de casas para realocação das famílias em situação } \\
\text { de vulnerabilidade. }\end{array}$ \\
\hline $\begin{array}{l}\text { Programa Cor Arrastão - Eixo } \\
\text { Habitação Social }\end{array}$ & $\begin{array}{l}\text { Projeto de revitalização das fachadas das casas, por meio de mutirão, usando } \\
\text { a arte como força mobilizadora. O projeto fornece também assistência técnica } \\
\text { e crédito para as famílias realizarem melhorias em suas residências, além de } \\
\text { auxiliar processos de organização dos moradores e de formação de uma rede de } \\
\text { profissionais de setores variados. }\end{array}$ \\
\hline Programa Estrutural em Áreas de Risco & $\begin{array}{l}\text { Programa de assistência técnica que atua nos aspectos físico e social, prestando } \\
\text { atendimento contínuo às famílias moradoras de áreas de risco geológico } \\
\text { residentes em vilas e favelas. O programa é constituído por três planos: o Plano } \\
\text { de Atendimento Emergencial, que proporciona atendimento nas áreas de risco em } \\
\text { períodos chuvosos; o Plano de Mobilização Social, que promove orientação acerca } \\
\text { da atuação na prevenção de acidentes nas áreas de risco; e o Plano de Obras, } \\
\text { que visa executar obras pontuais e/ou estruturantes em áreas que apresentam } \\
\text { situação de risco. }\end{array}$ \\
\hline Programa Habitacional Vivendo Melhor & $\begin{array}{l}\text { Reformas de construções em condições precárias e/ou realização de obras } \\
\text { de ampliação nas residências da população de baixa renda. As melhorias são } \\
\text { realizadas por meio de uma política pública que desenvolve ações para propiciar } \\
\text { mudanças na realidade social das famílias, cujos beneficiários são selecionados } \\
\text { através de critérios socioeconômicos e recebem orientações acerca da conservação } \\
\text { de suas residências e do plantio de horta e árvores. }\end{array}$ \\
\hline
\end{tabular}


(Continuação)

\begin{tabular}{|l|l|}
\hline TS & \multicolumn{1}{c|}{ Descrição da TS } \\
\hline $\begin{array}{l}\text { Projeto Arquiteto de Família - } \\
\text { Habitação Saudável e Sustentável }\end{array}$ & $\begin{array}{l}\text { Assistência técnica para a realização de reforma de moradias nas comunidades de } \\
\text { baixa renda, tendo como peculiaridades a aquisição de materiais de construção em } \\
\text { feiras de trocas, o acesso a microcrédito habitacional e a realização de mutirão. }\end{array}$ \\
\hline Projeto Habitat de Ação Imediata & $\begin{array}{l}\text { Prestação de assessoria técnica, mediante elaboração de projetos arquitetônicos, } \\
\text { orçamentos, orientação técnica e acompanhamento da execução de reformas e/ou } \\
\text { ampliação e construção de residências, para atender às famílias beneficiadas com } \\
\text { doação de materiais de construção. }\end{array}$ \\
\hline $\begin{array}{l}\text { Transformando Realidades por meio da } \\
\text { Mobilização e Organização Comunitária }\end{array}$ & $\begin{array}{l}\text { Baseia-se na metodologia do Slum Dwellers Internacional (SDI), que tem como } \\
\text { tripé poupança comunitária, autorrecenseamento e intercâmbio de experiências, } \\
\text { visando contribuir para que as comunidades em assentamentos precários ou } \\
\text { favelas conquistem seus direitos de cidadania e moradia, por meio da organização } \\
\text { comunitária e do reconhecimento de seu potencial transformador e multiplicador. }\end{array}$ \\
\hline $\begin{array}{l}\text { Wikimapa - Localização ao Alcance } \\
\text { de Todos }\end{array}$ & $\begin{array}{l}\text { Mapa virtual colaborativo de pontos de interesse público em áreas marginalizadas, } \\
\text { alimentado por moradores de favelas a partir da inserção e edição de informações } \\
\text { que permitem o mapeamento de locais e eventos, além do registro de ruas ainda } \\
\text { não identificadas nos mapas virtuais. }\end{array}$ \\
\hline
\end{tabular}

Fonte: FBB. Disponível em: <https://is.gd/3qeC1S>.

Elaboração dos autores.

Foram analisadas as características gerais da tecnologia, incluindo:

- tema secundário;

- os Objetivos de Desenvolvimento Sustentável (ODS) em que as tecnologias foram enquadradas;

- objetivo da TS (solução apresentada);

- instituição responsável por seu desenvolvimento (localização e natureza jurídica); ${ }^{18}$

- locais para os quais foram disseminadas;

- instituiçôes parceiras, incluindo o tipo de apoio;

- mão de obra utilizada;

- impacto ambiental; e

- o modo como foi feita a difusão das tecnologias. ${ }^{19}$

Parte dessa análise tem como base a classificação feita pela própria FBB, e parte foi elaborada a partir das informações disponíveis nos relatórios descritivos das TS.

As tecnologias habitacionais apresentaram como áreas de atuação complementar - chamadas no BTS de temas secundários - meio ambiente e renda, além de saúde e educação. De forma análoga, entre os ODS, as tecnologias habitacionais foram classificadas, em ordem decrescente de número de tecnologias que as menciona, em: ODS 11 - Cidades e comunidades sustentáveis;

18. Natureza jurídica não consta no BTS. A partir do nome das instituições, os autores identificaram o Cadastro Nacional da Pessoa Jurídica (CNPJ). A classificação dessas instituições foi realizada pela busca do CNPJ no sítio da Receita Federal do Brasil: <https:// goo.gl/ewz5VU>.

19. Ressalta-se que essa análise considerou somente as informações que estavam disponíveis no BTS, portanto elementos que, eventualmente, não tenham sido fornecidos pela instituição responsável pela criação da tecnologia não foram contemplados. 
ODS 4 - Educação de qualidade; ODS 8 - Trabalho descente e crescimento econômico; ODS 12 - Consumo e produção responsáveis; ODS 13 - Ação contra a mudança global do clima; ODS 17 - Parcerias e meios de implementação; e, por fim, ODS 3 - Saúde e bemestar. Essa associaçáo não surpreende, dado que a relação entre as melhorias na habitação e os temas secundários e ODS citados é amplamente conhecida. A construção e reforma de casas mobiliza mão de obra, gerando renda; pode melhorar as condiçóes de saúde dos moradores e ambientais de seu entorno; e promove práticas educativas, como reciclagem, entre a populaçấo.

Visando entender em maior detalhe o objetivo das tecnologias desenvolvidas, ou seja, as características das soluçóes apresentadas, as TS foram classificadas pelos autores em: acesso à terra, assistência técnica, construção, produçáo de conteúdo digital, produtos, reforma e, por fim, reutilização e reciclagem. Cada um desses objetivos gerais foi dividido em objetivos específicos. No caso de produtos, por exemplo, encontra-se o desenvolvimento de calhas alternativas, tijolos ecológicos e placas numéricas. A tabela 1 apresenta os objetivos principais e específicos e quantas tecnologias foram classificadas em cada um deles, sendo que cada TS pode ter sido classificada em mais de uma categoria.

TABELA 1

\section{Classificação das TS pelos objetivos principais e específicos}

\begin{tabular}{llc}
\hline Objetivos principais & \multicolumn{1}{c}{ Objetivos específicos } & Número de TS \\
\hline Acesso à terra & Acesso à terra & 1 \\
\hline \multirow{3}{*}{ Assistência técnica } & Áreas de risco & 1 \\
& Capacitação & 3 \\
& Organização comunitária & 1 \\
& Projeto arquitetônico e orientação técnica & 3 \\
\hline \multirow{3}{*}{ Construção } & Construção de novas moradias & 8 \\
& Substituição de moradias precárias anteriormente existentes & 7 \\
Produção de conteúdo digital & Mapa virtual colaborativo & 1 \\
& Portal multimídia & 2 \\
\hline \multirow{3}{*}{ Produtos } & Calhas alternativas & 1 \\
& Placas numéricas de mosaico & 1 \\
\hline \multirow{2}{*}{ Reforma } & Tijolos ecológicos & 5 \\
& Reforma geral & 5 \\
& Revitalização de fachada & 1 \\
\hline & Reciclagem de materiais & 2 \\
& Reciclagem de embalagens & 1 \\
& Reciclagem de óleo de cozinha & 1 \\
Reutilização e reciclagem & Reúso de materiais & 3 \\
& Reúso de embalagens & 1 \\
& Uso de materiais fabricados com embalagens recicladas & 1 \\
\hline
\end{tabular}

Fonte: FBB. Disponível em: <https://is.gd/3qeC1S>.

Elaboração dos autores. 
A maioria das instituiçóes responsáveis pelo desenvolvimento das TS foram associações privadas, que inclui ONGs, mas também aparecem como instituiçóes relevantes as prefeituras e as cooperativas. Entidade sindical, fundação pública de direito público federal e autarquia federal aparecem como criadoras de uma TS cada. O Sudeste é a principal regiáo de origem das instituiçôes responsáveis pelo desenvolvimento de TS habitacionais, com destaque para os estados do Rio de Janeiro e de São Paulo. Essas tecnologias também surgiram em Santa Catarina, na Bahia, na Paraíba, em Pernambuco e em Mato Grosso do Sul. Duas instituiçóes eram estrangeiras, uma sediada na Argentina e a outra no Chile. Em relação à reaplicação, as tecnologias analisadas foram majoritariamente implementadas apenas no lugar de origem. Essa informaçáo revela a baixa difusáo da maior parte dessas iniciativas, dada a sua limitada reaplicação até o momento analisado.

Para o desenvolvimento e a reaplicação das TS, as responsáveis por sua criação possuem parcerias com diversas outras instituiçóes. Nessas parcerias, os autores identificaram os seguintes objetivos:

- auditoria;

- apoio financeiro;

- doação - de moradias, materiais de construção, móveis, utensílios domésticos, entre outros;

- mão de obra - capacitação, seleção, supervisão e pagamento de mão de obra;

- institucional - apoio de instituições públicas, como secretarias, ministério público, entre outras;

- mobilização social;

- reciclagem de embalagens; e

- técnico - envolvem a elaboração e o desenvolvimento de projetos (inclusive arquitetônicos), a construção de metodologias, a liberação de crédito e a ordenação de pagamentos, o acompanhamento e a gestão das obras, a organização das famílias e a extensão universitária.

Entre essas parcerias, os apoios técnico e financeiro foram as principais formas de suporte fornecido às instituiçôes responsáveis pela criação das TS. E, especificamente em relação ao apoio financeiro, este originou-se de instituiçóes tanto públicas como privadas, nacionais e estrangeiras.

Em relação à força de trabalho, verificou-se que a maior parte das TS utilizou mão de obra especializada, o que minimiza a possibilidade de implementação inadequada, tão comum no campo habitacional. Ademais, os próprios moradores contribuem na implementação de grande parte das TS, característica também comum nesse setor. Entre as 27 tecnologias, 18 incluem tanto mão de obra especializada quanto moradores e voluntários, interação que pode auxiliar no processo de capacitação dos usuários (tabela 2). 
TABELA 2

Classificação das TS por tipo de mão de obra utilizada

\begin{tabular}{lc}
\hline Força de trabalho & Número de TS \\
\hline Mão de obra especializada & 23 \\
Arquitetos e/ou engenheiros e/ou estudantes dessas áreas & 14 \\
Profissionais da área social (assistentes sociais, sociólogos, entre outros) & 11 \\
Os próprios moradores & 20 \\
Voluntários & 6 \\
Outros & 4 \\
\hline
\end{tabular}

Fonte: FBB. Disponível em: <https://is.gd/3qeC1S>.

Elaboração dos autores.

Os impactos ambientais foram classificados por área. Como se pode observar na tabela 3, os principais impactos das tecnologias habitacionais analisadas dizem respeito a: práticas de reaproveitamento; reutilizaçáo e reciclagem (resíduos sólidos); formas de reutilizaçáo ou melhoria da qualidade da água (recursos hídricos); e todos os tipos de conservação e preservação ambiental (biodiversidade). Algumas TS também realizam práticas de promoção de educação ambiental, além de fazerem uso de energias menos poluentes (energias renováveis) e gerarem impacto positivo para evitar a degradaçáo do solo (qualidade do solo) e melhorar a qualidade do ar.

\section{TABELA 3}

\section{Classificação das TS por tipo de impacto ambiental}

\begin{tabular}{lc}
\hline Impacto ambiental & Número de TS \\
\hline Resíduos sólidos & 14 \\
Recursos hídricos & 12 \\
Biodiversidade & 10 \\
Educação ambiental & 7 \\
Energias renováveis & 4 \\
Qualidade do solo & 4 \\
Qualidade do ar & 3 \\
\hline
\end{tabular}

Fonte: FBB. Disponível em: <https://is.gd/3qeC1S>.

Elaboração dos autores.

Tão importante quanto analisar a implementação de uma tecnologia é verificar a sua possibilidade de reaplicação e os mecanismos utilizados para difundi-la. As formas de difusão das tecnologias identificadas foram: audiovisual, que engloba a produção de vídeos e documentários; banco de dados; capacitação, que compreende cursos, oficinas, palestras, treinamentos e workshops; multiplicadores, que diz respeito à capacidade de os beneficiários da tecnologia em uma determinada comunidade atuarem como difusores do conhecimento da TS em outras comunidades; participação em eventos, congressos e eventos ligados a universidades; produção de conteúdo escrito, que podem ser cartilhas, manuais, apostilas, tutoriais, publicações 
acadêmicas e matérias jornalísticas; e visita às unidades onde as TS foram implantadas. Entre essas, os meios mais relevantes de difusão das tecnologias habitacionais em análise foram a produção de conteúdo escrito, a capacitação e o audiovisual (tabela 4).

TABELA 4

Classificação das TS por formas de difusão da tecnologia

\begin{tabular}{lc}
\hline Formas de difusão da tecnologia & Número de TS \\
\hline Produção de conteúdo escrito & 14 \\
Capacitação & 13 \\
Audiovisual & 7 \\
Multiplicadores & 5 \\
Participação em eventos & 3 \\
Banco de dados & 1 \\
Visita às unidades prontas & 1 \\
\hline
\end{tabular}

Fonte: FBB. Disponível em: <https://is.gd/3qeC1S>.

Elaboração dos autores.

Uma limitação importante para a difusão de inovaçóes no campo habitacional, incluindo TS, viria dos próprios consumidores, uma vez que muitos têm preconceito em relação a projetos habitacionais não convencionais (Bredenoord, 2016), tendo preferência por materiais e técnicas tradicionais (Moraes e Santana, 2003). Materiais que transmitem uma ideia de fragilidade, ainda que irreal, entrariam em conflito com a cultura construtiva brasileira, baseada em materiais maciços e com pouca exigência de manutenção (Castro e Kruger, 2013).

\section{CONSIDERAÇÕES FINAIS}

A análise apresentada buscou identificar as características das TS habitacionais presentes no BTS da FBB. Todavia, apesar do potencial das TS para minimizar impactos sociais e ambientais, é importante ter cautela sobre sua abrangência. Como ressalta Corrêa (2010), é necessário diferenciar com clareza soluçôes estruturantes das assistencialistas, que somente atuam de forma paliativa nos cenários de vulnerabilidade. Por sua vez, Thomas (2009) destaca que, no afã de se encontrarem tecnologias voltadas aos mais vulneráveis, corre-se o risco de sacramentar a discriminação ao direcionar a esse grupo somente equipamentos de baixa tecnologia ou mesmo arcaicos. Portanto, as TS devem ser estimuladas quando aparecem como a melhor solução para problemas específicos, permitindo tanto o envolvimento da comunidade quanto a sua apropriação do conhecimento, e não como substituto "barato", ainda que inadequado, para atender aos mais necessitados e vulneráveis. 


\section{REFERÊNCIAS}

BANCO MUNDIAL. Sustainable low-income housing in Brazil. Brasil, 2011. Disponível em: <https://bit.ly/3eDpYrf>. Acesso em: 8 dez. 2019.

BREDENOORD, J. Sustainable housing and building materials for low-income households. Journal of Architectural Engineering Technology, v. 5, n. 1, p. 1-9, 2016.

CASTRO, M. L.; KRUGER, P. G. Unidades de seleção tecnológica e inovação na construção habitacional no Brasil. Ambiente Construído, v. 13, n. 3, 2013.

CORREA, R. F. Tecnologia e sociedade: análise de tecnologias sociais no Brasil contemporâneo. 2010. Dissertação (Mestrado em Sociologia) - Universidade Federal do Rio Grande do Sul, Porto Alegre, 2010.

FJP - FUNDAÇÃO JOÃO PINHEIRO. Deficit habitacional no Brasil 2015. Belo Horizonte: FJP, 2018.

LASSANCE JUNIOR, A. E.; PEDREIRA, J. S. Tecnologias sociais e políticas públicas. In: LASSANCE JUNIOR, A. E. et al. Tecnologia social: uma estratégia para o desenvolvimento. Rio de Janeiro: FBB, 2004. p. 65-82.

MORAES, O. B.; SANTANA, M. J. A. Tecnologia, habitação e desenvolvimento sustentável. In: ENCONTRO NACIONAL SOBRE EDIFICAÇÕES E COMUNIDADES SUSTENTÁVEIS, 3., 2003, São Carlos, São Paulo. Anais... 2003. São Carlos: Antac, 2003.

THOMAS, H. Tecnologías para la inclusión social y políticas públicas en América Latina. In: OTTERLLO, A. et al. Tecnologias sociais: caminhos para a sustentabilidade. Brasília, 2009.

URUSHIBATA, C. Programas de melhoria habitacional em favelas pós-urbanizadas: experiências nos municípios de Taboão da Serra e Diadema. 2013. Dissertação (Mestrado) Instituto de Pesquisas Tecnológicas, São Paulo, 2013.

ZUCOLOTO, G. F.; PEREIRA, L. S. Tecnologias sociais e economia solidária: projetos certificados pela Fundação Banco do Brasil. In: SILVA, S. P. (Org.). Dinâmicas da economia solidária no Brasil: organizaçóes econômicas, representaçóes sociais e políticas públicas. Brasília: Ipea, 2020. 
Ipea - Instituto de Pesquisa Econômica Aplicada

\section{EDITORIAL}

Chefe do Editorial

Reginaldo da Silva Domingos

Assistentes da Chefia

Rafael Augusto Ferreira Cardoso

Samuel Elias de Souza

\section{Supervisão}

Camilla de Miranda Mariath Gomes

Everson da Silva Moura

\section{Editoração}

Aeromilson Trajano de Mesquita

Anderson Silva Reis

Cristiano Ferreira de Araújo

Danilo Leite de Macedo Tavares

Jeovah Herculano Szervinsk Junior

Leonardo Hideki Higa

The manuscripts in languages other than Portuguese published herein have not been proofread.

\section{Livraria Ipea}

SBS - Quadra 1 - Bloco J - Ed. BNDES, Térreo

70076-900 - Brasília - DF

Tel.: (61) 2026-5336

Correio eletrônico: livraria@ipea.gov.br 



\section{Missão do Ipea}

Aprimorar as políticas públicas essenciais ao desenvolvimento brasileiro por meio da produção e disseminação de conhecimentos e da assessoria ao Estado nas suas decisões estratégicas.

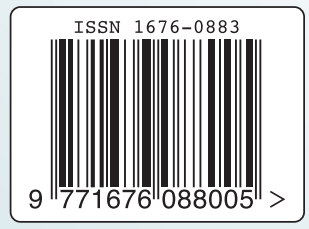

ECONOMIA

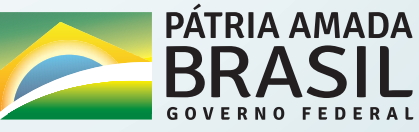

